\title{
Aquatic Macroinvertebrates of the Lower Missouri River
}

The U.S. Geological Survey (USGS) Columbia Environmental Research Center (CERC), in cooperation with the U.S. Environmental Protection Agency (USEPA), the U.S. Fish \& Wildlife Service (USFWS), and the Missouri Department of Natural Resources (MDNR), has been conducting research on the aquatic macroinvertebrates of the lower Missouri River since the mid-1990s. This research was initiated in response to the need for comprehensive characterization of biological communities inhabiting aquatic habitats in large river systems that have historically been poorly studied. The USGS Status and Trends of Biological Resources Program provided partial funding for pilot studies that began in 1993 when the CERC was part of the USFWS. The purpose of this fact sheet is to provide stakeholders, scientists, management, and the general public with a basic summary of results from studies conducted by the CERC since that time period.

\section{Background}

\section{on Aquatic}

\section{Macroinvertebrates}

Macroinvertebrates are small organisms without a backbone (vertebrae) that are visible to the naked eye, and they may be either pelagic (free swimming in the water column) or benthic (attached to bottom substrates or burrowed into sediments). Macroinvertebrates are often the most abundant and diverse group of animals found in freshwater, and they include insects, mussels, snails, worms, and all crustaceans (crayfish, shrimp). In many types of water bodies, insects are the most dominant and diverse group of macroinvertebrates. The immature stages of many insects spend most of their time growing and feeding in aquatic habitats before they emerge as a winged adult. In insect groups that have gradual metamorphosis, the aquatic life cycle stages are known as nymphs or naiads, and in aquatic insects with complete metamorphosis, these stages are known as larvae or pupae. Macroinvertebrates are a primary food base for many fishes, birds, amphibians, reptiles, and mammals, such as bats and raccoons. They process organic matter by breaking down leaves and woody material that fall into water. Macroinvertebrates are part of all aquatic food webs, representing every major feeding type, including predators, scrapers, collectors, shredders, and filterers.

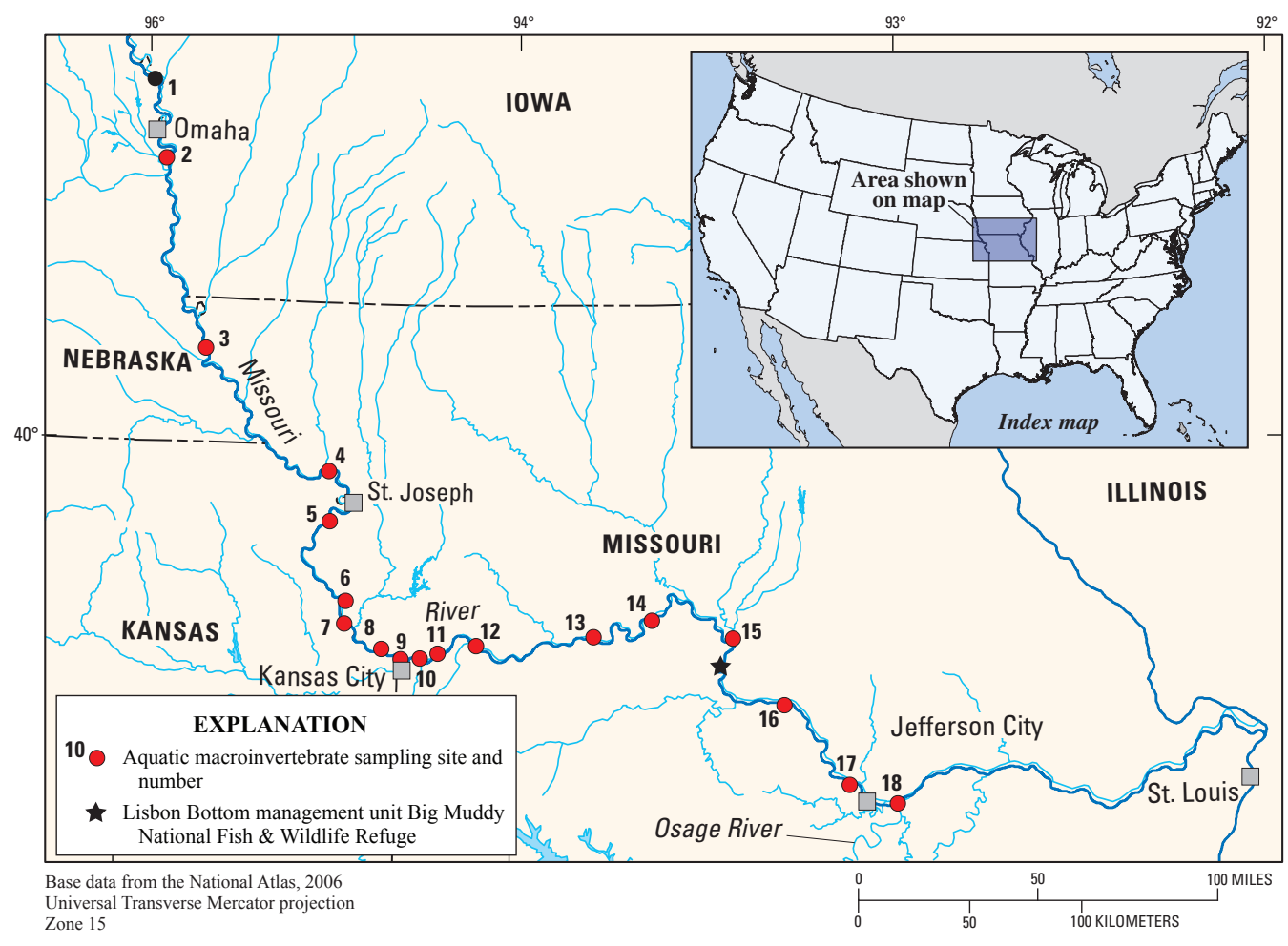

Figure 1. Map showing 18 aquatic macroinvertebrate sampling sites in the lower Missouri River, and location of the wetland complex at Lisbon Bottom. 


\section{Indicators of Environmental Quality}

Aquatic macroinvertebrates are one of the most sensitive indicators for measuring the quality of streams, rivers, lakes, and wetlands. Scientists survey aquatic communities as a measure of ecological condition or "health," because these communities provide clues related to the past history of exposure to environmental stressors such as degraded water quality, effects of habitat loss, declines in substrate quality, and presence of contaminants. By examining the number of species, abundance, and the relative proportion of different feeding types, scientists are able to evaluate the quality (or, "biotic condition") of individual habitats, study sites, river reaches, or entire systems. These types of studies are known as biological assessments. Even though macroinvertebrates are the most frequently utilized aquatic
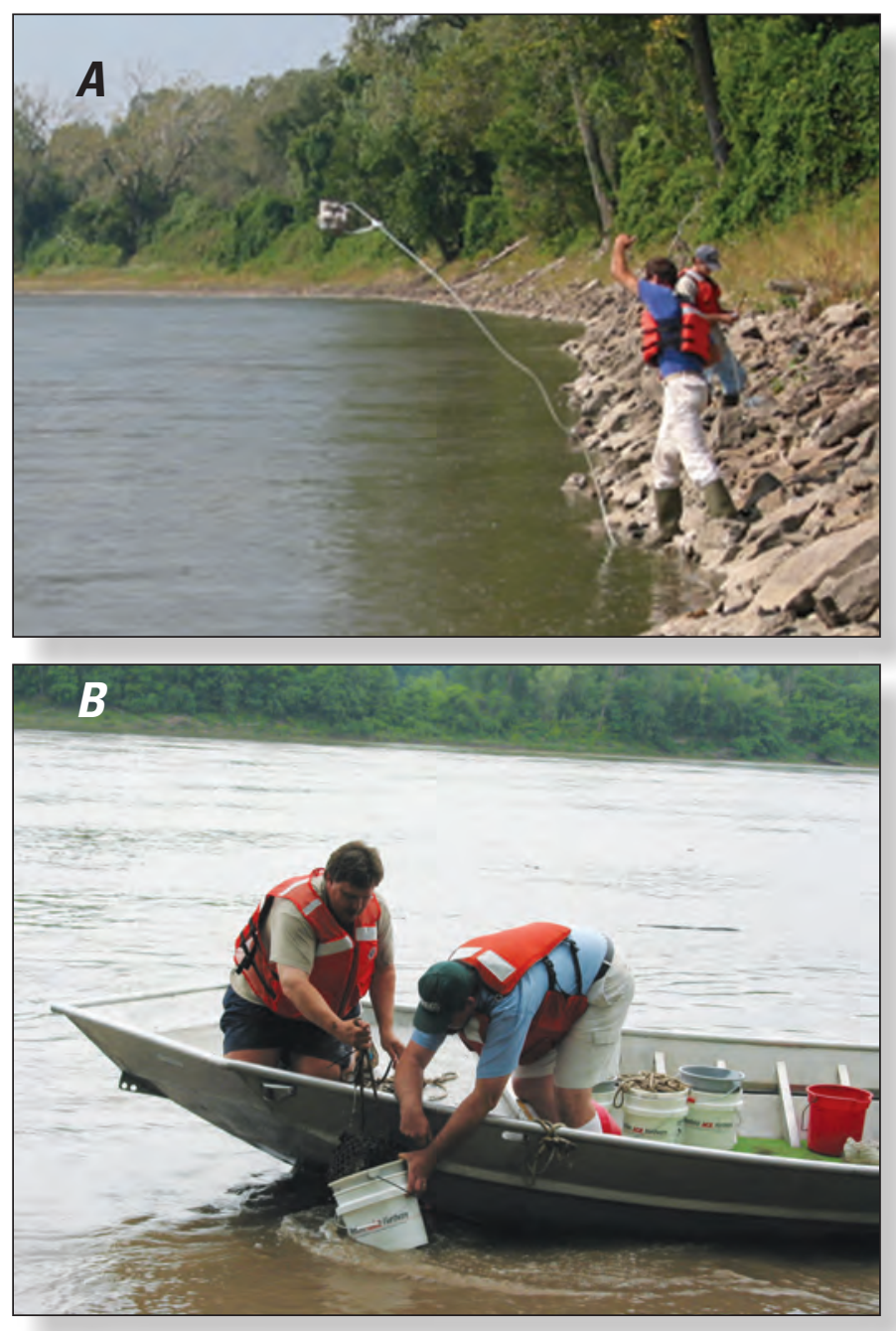

Figure 2. A rock basket artificial substrate sampler, used to collect aquatic macroinvertebrates from deep water zones at outside bend revetments. Samplers are allowed to colonize with organisms for 4-6 weeks before retrieval, sample preservation, and laboratory processing. $A=$ deployment, $B=$ boat retrieval.

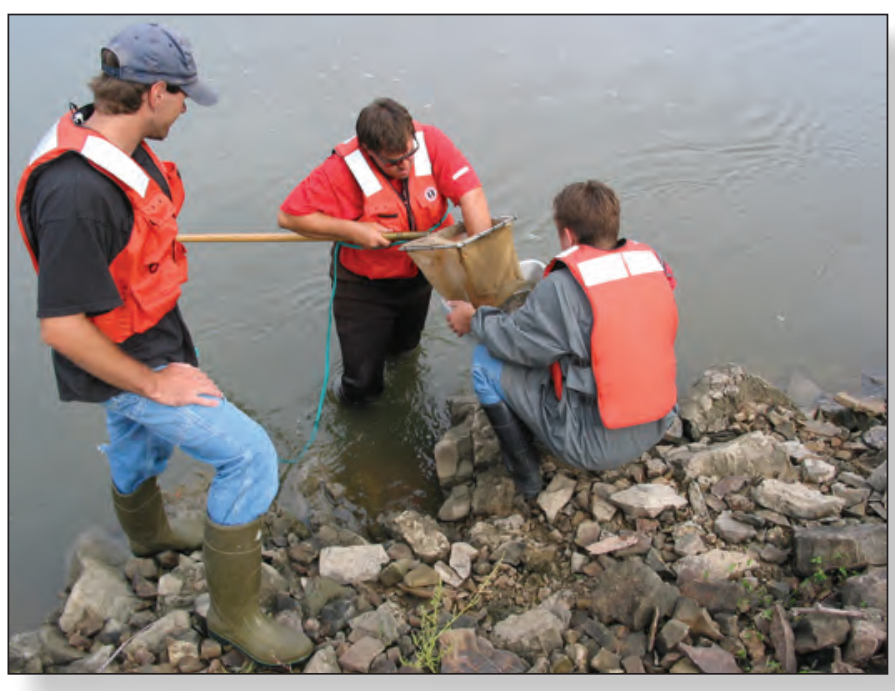

Figure 3. Sampling aquatic macroinvertebrates with a D-frame kick net from shoreline areas in the lower Missouri River. At several locations, coarse substrate is physically disturbed while the current flow carries dislodged organisms into the net.

component for these assessments, other communities such as algae, zooplankton, vascular plants, and fishes are also being studied. By combining aquatic community indicators with other measurements such as water chemistry, sediment quality, and habitat evaluations, scientists can develop a numerical score or rating for individual sites or watersheds and relate them to aquatic ecosystems that are relatively free from human disturbance.

\section{Macroinvertebrates in Water Resource Regulation}

The Clean Water Act (CWA) of 1972 outlines guidance measures to assure that all water bodies in the United States can achieve an acceptable level of aquatic life that is similar in structure and function to that of natural, undisturbed systems. This CWA goal is known as "biotic integrity." Because macroinvertebrate communities are sensitive to the effects of past disturbances or changes in system quality, they are utilized for determining whether a water body can support an acceptable level of aquatic life. This makes them especially important for water resource regulation and management and for measuring the success of restoration activities and other system improvements. Natural resource agencies in several States have developed restoration targets and aquatic life attainment goals for ecoregions, watersheds, or particular water bodies so that they can more effectively inventory the status of water bodies within 


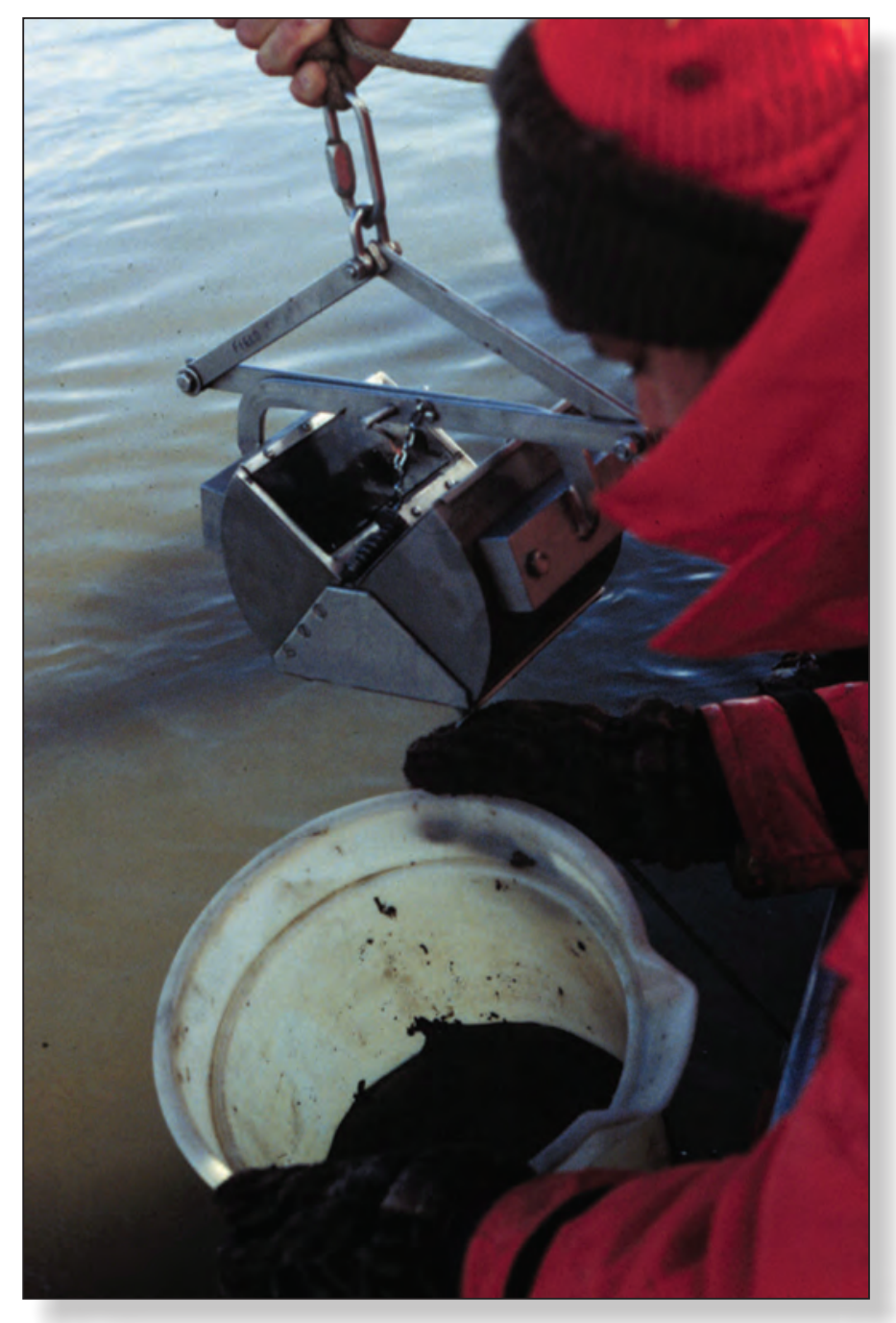

Figure 4. The ponar grab, used to sample macroinvertebrates inhabiting fine sediments from dike pool habitats. Samples are rinsed with a sieve bucket in the field before preservation.

their jurisdictions as part of the CWA requirements. These are referred to as biological criteria, which can be narrative statements describing community characteristics necessary for maintaining aquatic life or numerical values that are acceptable for a water body to fully meet its designated uses. A few States have developed biological criteria for macroinvertebrate community indicators and are currently utilizing these criteria to measure levels of impairment in aquatic systems.

\section{Lower Missouri River Macroinvertebrates}

Compared to smaller, wadeable streams, aquatic life inhabiting our largest river systems in the United States has not been adequately characterized. The channelized lower Missouri River system is perhaps the poorest known because unlike the Mississippi and Ohio Rivers, very few comprehensive research studies have been completed for macroinvertebrates. Larger river systems typically contain different habitats that are more difficult to sample effectively with standard gear types, and the composition of aquatic species also differs. Since the mid-1990s, a series of research studies was conducted on the channelized lower Missouri River by scientists at the CERC. These studies were initiated to characterize macroinvertebrate diversity and composition in specific habitat and substrate types and to develop efficient sampling methodologies. In addition to these studies conducted in mainstem habitats, a floodplain wetland complex (Lisbon Bottom management unit of the Big Muddy National Fish \&Wildlife Refuge, Columbia, Mo., see fig. 1) was thoroughly surveyed in 1999 to characterize macroinvertebrate diversity and abundance in different wetland types during preflood and postflood conditions. To provide supplementary support for all of these studies, samples of winged adult insects were taken with a blacklight trap during spring, summer, and fall seasons to confirm specieslevel identification and to enhance estimates of floodplain biodiversity.

Within the last two decades, because the impairment status of aquatic life in large rivers has been poorly understood, scientists have begun to develop

\section{Number of species (142 total)}

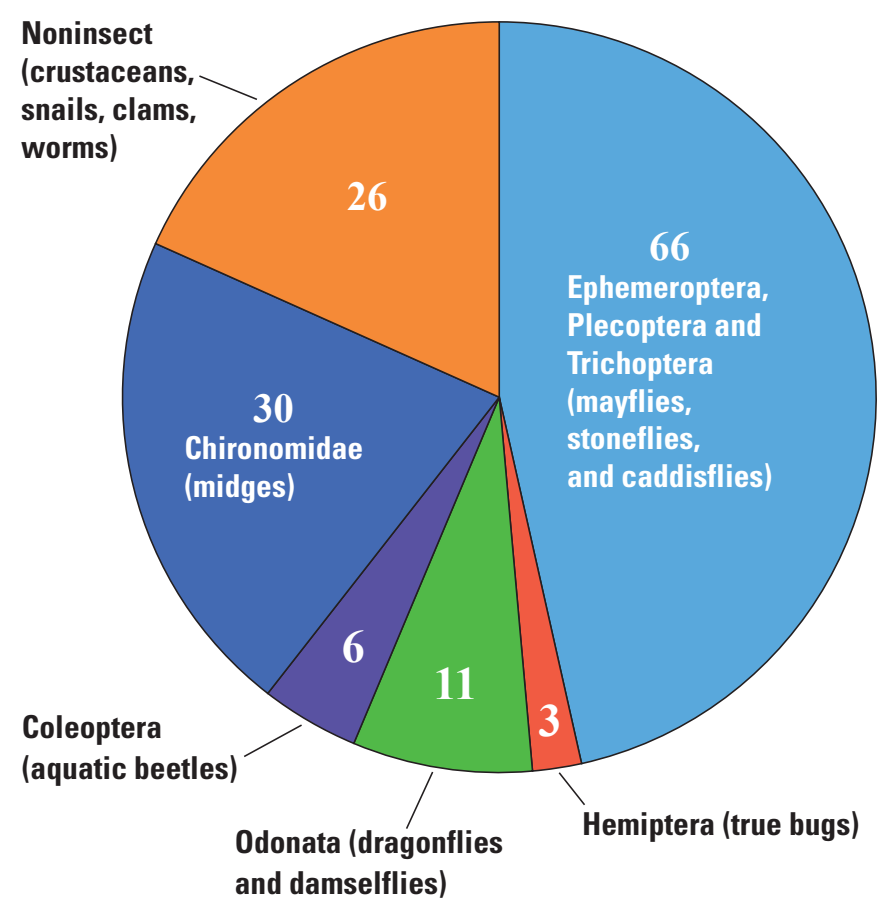

Figure 5. Species of aquatic macroinvertebrates known to occur in the mainstem of the lower Missouri River, by invertebrate group. 


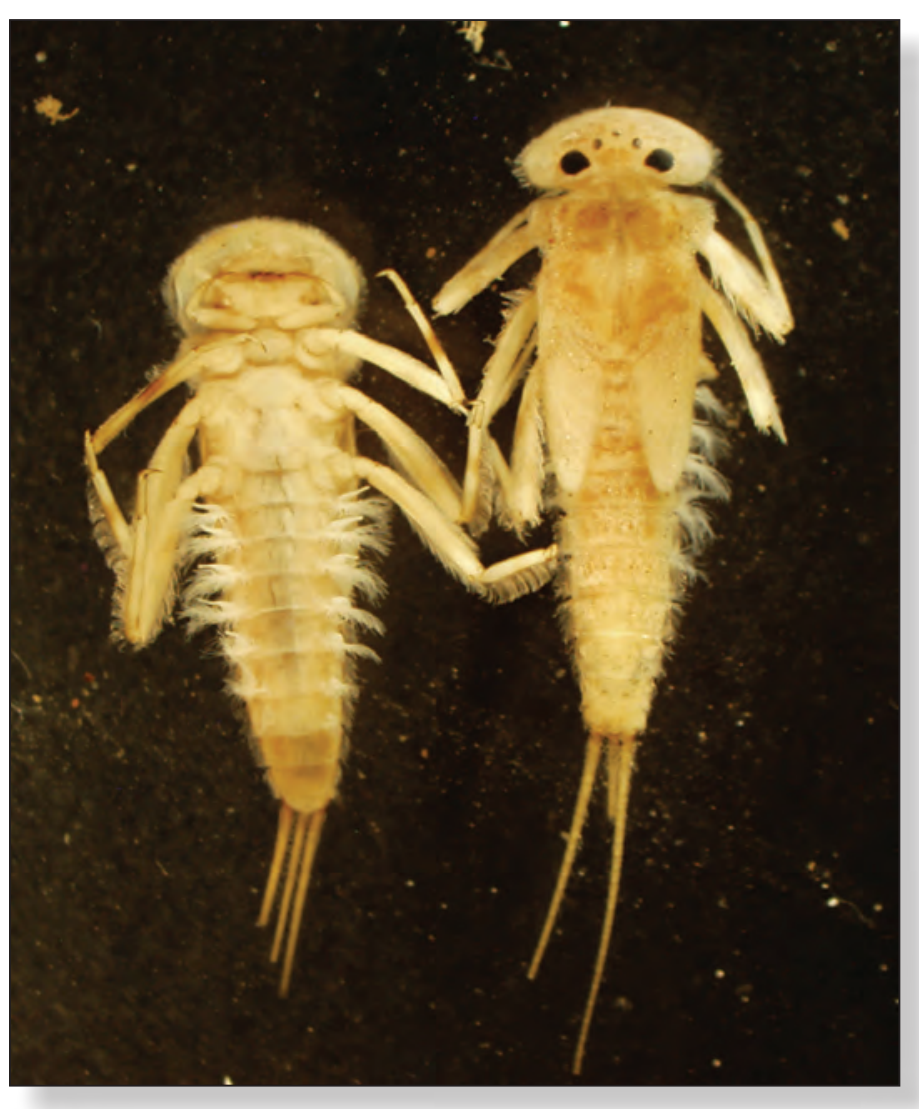

Figure 6. A rare, flat-headed mayfly species (Raptoheptagenia cruentata, ventral and dorsal views) restricted to large rivers. Nymphal stages of this mayfly can be found attached to solid surfaces such as rocks or large woody debris (Photo by Amy Meier, Missouri Department of Conservation, used with permission).

ecological evaluation frameworks that utilize biological assessment data for evaluating the quality of these large systems. The most recent research conducted by the CERC scientists on macroinvertebrates in the channelized reaches of the lower Missouri River (2002-2005) included a comprehensive study designed to evaluate the quality of specific habitats and to validate macroinvertebrate indicator responses to longitudinal gradients in water quality, sediment quality, and levels of contaminants. The study included evaluations of all previously surveyed lower Missouri River sites (18 total) from upstream of Omaha, Nebr., to the mouth of the Osage River in central Missouri (fig. 1). Two key, distinct habitats that are repeatable within this river reach were sampled with different methods. Rock revetments at outside meander bends were sampled with rock-basket artificial substrates (figs. $2 A$ and $2 B$ ) and a D-frame kick net (fig. 3). Backwater pools downstream of large wing dikes that contain fine sediments were sampled with a Ponar grab (fig. 4).
Listed below are preliminary findings based on aquatic macroinvertebrate studies conducted by scientists at the CERC in the channelized lower Missouri River.

\section{Species Diversity and Composition}

- Highest diversity and abundance occurs in the most stable and heterogeneous substrates with moderate current velocities, such as that found on rock revetments and wing dikes.

- About 142 species are known to occur in the mainstem of the river (fig. 5), nearly half of which belong to the three primary insect orders found in flowing waters -Ephemeroptera (mayflies), Plecoptera (stoneflies), and Trichoptera (caddisflies).

- In the mainstem, 22 species are restricted to large rivers (obligates, see figs. 6 and 7), 7 species are listed for special conservation status by one or more States in the basin, and several species occur only in one habitat or type of bottom substrate.

- About 170 species are known to occur in off-channel wetlands, 132 of which are unique to wetlands and not found in the mainstem (fig. 8).

- One of the most diverse groups of insects in the river are the mayflies, with 47 species known to occur within mainstem and floodplain, including 11 burrowing species. The river also contains 6 mayfly species that are large-river obligates, 3 of which are adapted to live in sand habitats.

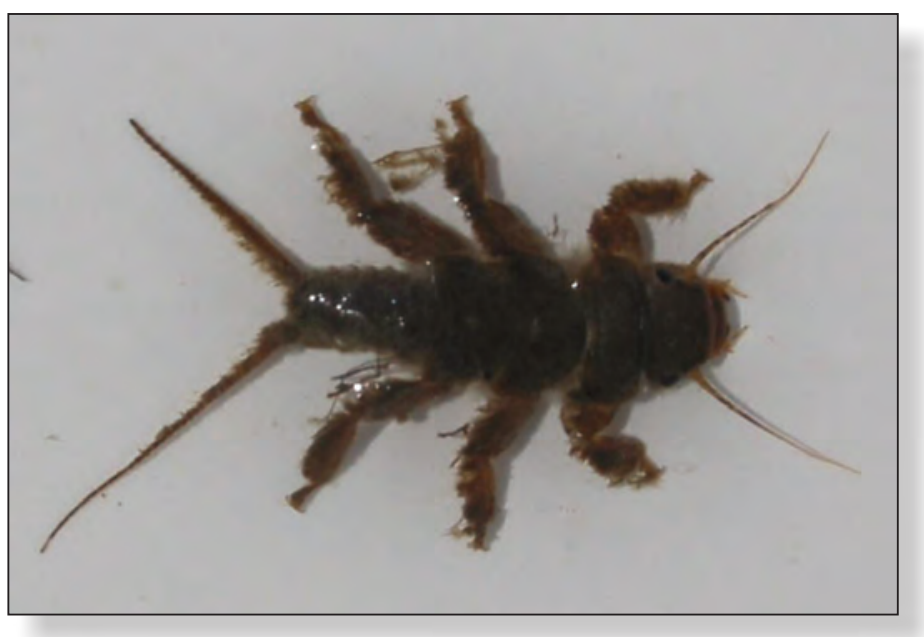

Figure 7. Nymph of a giant stonefly (Attaneuria ruralis) that inhabits rock crevices and woody debris snags. This species is a large river obligate, and the immature stage takes 1-2 years to develop before emerging in June. The winged adult stage is often attracted to lights. 


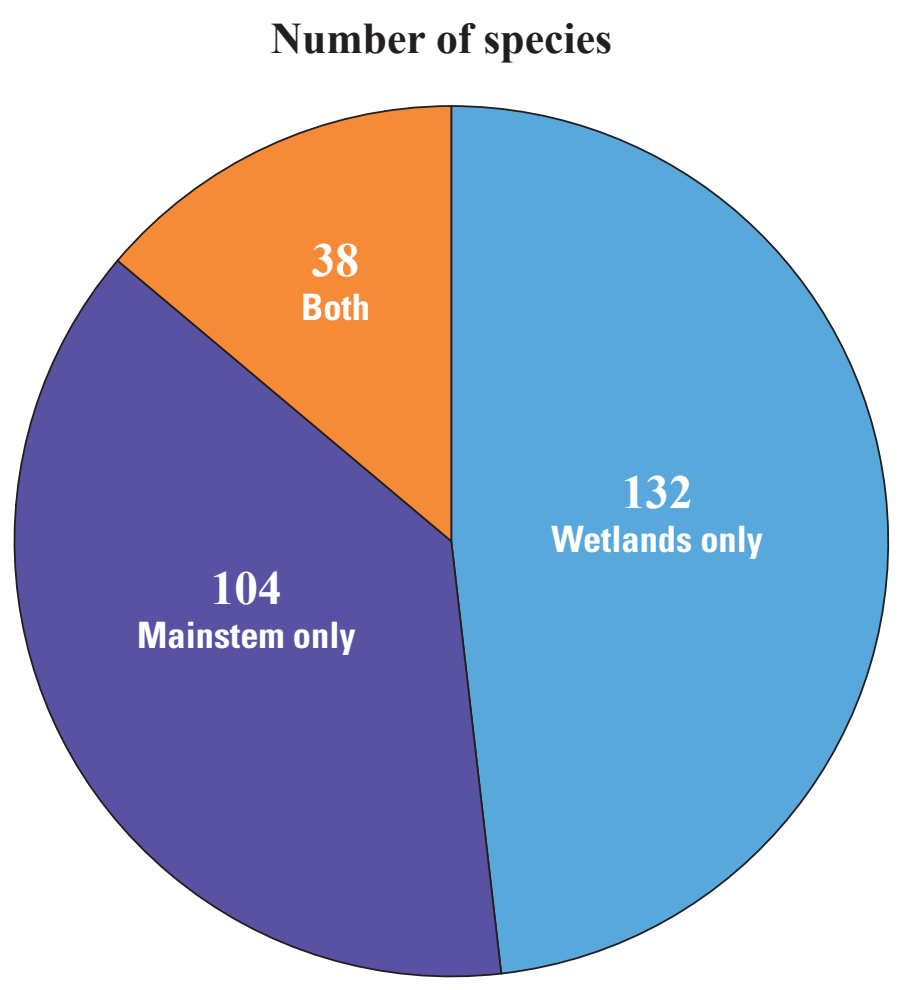

Figure 8. Comparison of aquatic macroinvertebrate species known to occur in the lower Missouri River mainstem with those inhabiting a flood-plain wetland complex (Lisbon Bottom management unit of the, Big Muddy National Fish \& Wildlife Refuge, Columbia, Mo.). About half of the species found in both mainstem and wetlands are riverine, and were transported into wetlands from the mainstem as a result of flooding.

\section{Density and Dominance}

- Estimates of macroinvertebrate density as measured by colonization of rock baskets ranged from $54,500 / \mathrm{m}^{2}$ just upstream of Omaha, Nebr., to $1,281,400 / \mathrm{m}^{2}$ at a site upstream of Kansas City, Mo.

- The most dominant macroinvertebrate group colonizing rock baskets were the net-spinning caddisflies (Hydropsychidae, fig. 9), which made up over 90 percent of the abundance at some river sites.

- Estimates of macroinvertebrate density in dike pools habitats ranged from $1,395-9489 / \mathrm{m}^{2}$, with the dominant group being the aquatic oligochaeta worms (Oligochaeta) at most sites. Midges (Chironomidae) and mayflies increased in dominance at the three most downstream sites where dike pools were larger in size and had better sediment quality.

- Estimates of macroinvertebrate density in off-channel wetlands were highest when vegetated margins were inundated and during postflood periods. This pattern occurred in both seasonal wetlands and scours (fig. 10).

\section{Biological Assessment}

- In dike pools, macroinvertebrate indicators responded to factors associated with oxygen-reducing conditions in sediments and to the presence of elevated concentrations of several contaminants

- Sites directly downstream of the Kansas City metropolitan area had lower biotic condition as compared to other sites.

- Biological assessments of large rivers can be conducted successfully by using similar evaluation frameworks, sampling methods, and communitylevel indicators as those used to evaluate biotic condition in small, wadeable flowing waters.

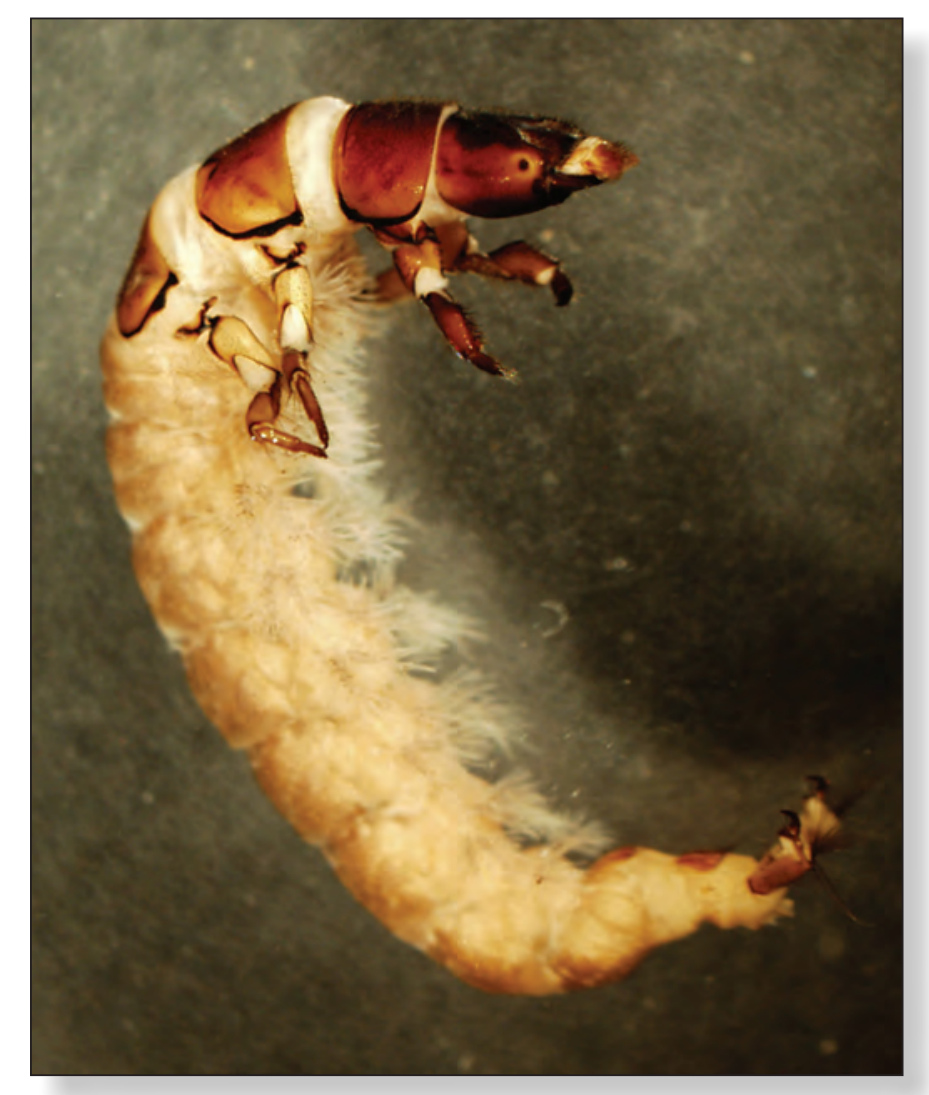

Figure 9. A net-spinning caddisfly (Hydropsyche orris) larvae that is one of the most abundant macroinvertebrates in the lower Missouri River. This group of caddisflies constructs silken capture nets attached to solid bottom substrates, which are used as a retreat and to filter fine particulate food from the water column (Photo by Amy Meier, Missouri Department. of Conservation, used with permission). 


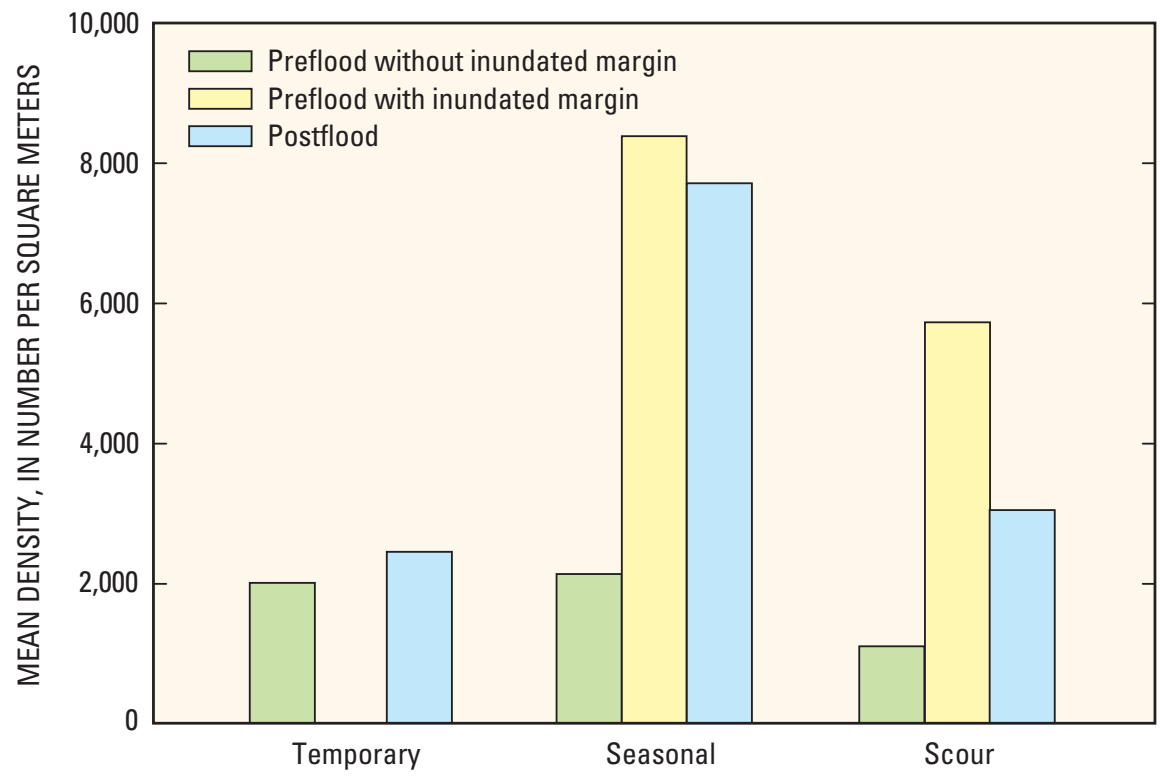

Figure 10. Aquatic macroinvertebrate density in 3 three different wetland types at the Lisbon Bottom management unit (Big Muddy National Fish \&Wildlife Refuge, Columbia, Mo.) during preflood- and post- flood periods (March-June, 1999), based on quantitative sampling along margins at different conditions related to inundation of shoreline vegetation.

\section{Selected References}

Angradi, T.R., Bolgrien, D.W., Jicha, T.M., Pearson, M.S., Hill, B.H., Taylor, D.L., Schweiger E.W., Shepard, Larry, Batterman, A.R., Moffett, M.F., Elonen, C.M., and Anderson, L.E., 2009, A bioassessment approach for mid-continent great riversthe Upper Mississippi, Missouri, and Ohio (USA): Environmental Monitoring and Assessment, v.152, no.1-4, p. 425-442.

Chapman, D.C., Ehrhardt, E.A., Fairchild, J.F., Jacobson, R.B., Poulton, B.C., Sappington, L.C., Kelly, B.P., and Mabee, W.R., 2004, Ecological dynamics of wetlands at Lisbon Bottom, Big Muddy Fish and Wildlife Refuge, Missouri: U.S. Geological Survey Open File Report 2004-1036, $166 \mathrm{p}$.

Echols, K.R., Brumbaugh, B.G., Orazio, C.E., May, T.W., Poulton, B.C., and Peterman, P.H., 2008, Distribution of pesticides, PAH's, PCB's, and bioavailable metals in depositional sediments of the lower Missouri River: Archives of Environmental Contaminants and Toxicology, v. 55, p. 161-172.
Poulton, B.C., Wildhaber, M.L., Charbonneau, C.S., Fairchild, J.F., Mueller, B.G., and Schmitt, C.S., 2003, A longitudinal assessment of the aquatic macroinvertebrate community in the channelized lower Missouri River: Environmental Monitoring and Assessment, v. 85, p. 23-53.

\section{For more information, contact:}

Barry C. Poulton, Research Ecologist U.S. Geological Survey

Columbia Environmental Research Center 4200 E. New Haven Road

Columbia, Missouri 65201

Phone: 573-876-1873

Email: bpoulton@usgs.gov

Or visit the Columbia Environmental Research Center Web site at: http://www. cerc.usgs.gov

Publication support provided by:

Rolla Publishing Service Center 